\title{
Structure Dependent Conductivity of Ultrathin ZnO Films
}

\author{
D. Snigurenko ${ }^{a} *$, K. Kopalko ${ }^{a}$, T.A. Krajewski ${ }^{a}$, G. Euka $^{a}$, S. Gieraltowska $^{a}$, \\ B.S. Witkowski ${ }^{a}$, M. Godlewski ${ }^{a, b}, \mathrm{~K}$. DyBko ${ }^{a}$, W. PAszkowicz ${ }^{a}$ And E. Guziewicz ${ }^{a}$ \\ ${ }^{a}$ Institute of Physics, Polish Academy of Sciences, al. Lotników 32/46, 02-668 Warsaw, Poland \\ ${ }^{b}$ Dept. of Mathematics and Natural Sciences College of Science, Cardinal S. Wyszyński University \\ Dewajtis 5, 01-815 Warsaw, Poland
}

\begin{abstract}
Zinc oxide films dedicated for hybrid organic/inorganic devices have been studied. The films were grown at low temperature $\left(100^{\circ} \mathrm{C}, 130^{\circ} \mathrm{C}\right.$ and $\left.200{ }^{\circ} \mathrm{C}\right)$ required for deposition on thermally unstable organic substrates. $\mathrm{ZnO}$ layers were obtained in atomic layer deposition processes with very short purging times in order to shift a structure of the films from polycrystalline towards amorphous one. The correlation between atomic layer deposition growth parameters, a structural quality and electrical properties of $\mathrm{ZnO}$ films was determined.
\end{abstract}

PACS: 73.61.Ga, 78.66.Hf, 81.15.Gh

\section{Introduction}

In recent years, the interest in thin films of wide-bandgap semiconductors has being increased rapidly. One of them is zinc oxide, which is currently widely investigated as a very promising II-VI semiconducting material for various electronic and optoelectronic purposes [1-3]. An important field of application of this material is organic electronics, in which $\mathrm{ZnO}$ deposited at a low temperature regime plays a role of an inorganic electrically active layer in devices $[4,5]$. $\mathrm{ZnO}$ is a very promising material here because, opposite to most of organic semiconductors, it reveals the $n$-type conductivity with a level of a carrier concentration that can be substantially tuned by manipulating the growth parameters [6]. Moreover, such thin $\mathrm{ZnO}$ films can be deposited at temperatures below $200{ }^{\circ} \mathrm{C}$ which is the stability limit for most of organic semiconducting materials.

Most of organic semiconductors degrade under normal atmospheric conditions and require application of a surface protection layer. Zinc oxide deposited on the surface of an organic semiconductor is an active part of a junction, but also can play a role of a protection layer of such hybrid organic/inorganic device. For the latter purpose a perfect adhesion is needed, which is not easy to achieve because of surface porosity of organic semiconductors. In this case a polycrystalline or even an amorphous $\mathrm{ZnO}$ film structure is recommended provided relevant electrical parameters.

On the other hand, a $\mathrm{ZnO}$ sublayer with decreased structural quality is always observed in the interface region and it is important to investigate its electrical prop-

\footnotetext{
* corresponding author; e-mail: snigurenko@ifpan.edu.pl
}

erties. Semiconductor films used in electronic devices are usually very thin (between $100 \mathrm{~nm}$ and $200 \mathrm{~nm}$ ), so such an interface layer is expected to significantly influence the electrical characteristic.

In the present study we investigated electrical parameters of ultrathin (thickness about $100 \mathrm{~nm}$ ) polycrystalline $\mathrm{ZnO}$ films deposited at the low temperature regime, i.e. a temperature adequate for application in hybrid organic/ inorganic devices. In dedicated series of atomic layer deposition (ALD) processes very short purging times were applied in order to shift polycrystalline growth towards amorphous one. For these films we determined correlation between ALD growth parameters, reduced structural quality and electrical properties.

\section{Experimental}

The polycrystalline $\mathrm{ZnO}$ layers were grown by ALD in the Savannah-100 reactor using diethylzinc and deionized water as zinc and oxygen precursors, respectively. As substrate we used silicon which was uniformly covered with the $\mathrm{ZnO}$ film in a double exchange reaction between precursors. Nitrogen was used as purging gas. Before the ALD growth process the substrates were sequentially rinsed in acetone, 2-propanol and deionized water. The growth processes were performed for 500 ALD cycles, which resulted in the film thickness between $70 \mathrm{~nm}$ and $100 \mathrm{~nm}$. The obtained thickness depends on the deposition temperature and is related to the ALD growth window [6].

In the present experiment we performed a series of deposition processes with a different ALD purging time that ranged from $0.1 \mathrm{~s}$ to $2 \mathrm{~s}$, while the rest of the ALD parameters (pulsing times and pressures) remained fixed. 
The ALD growth process consists of many deposition cycles and each of them consists of four stages: two pulsing times of both precursors and two purging times after precursors. The latter parameters influence a lot the crystallographic quality of deposited films. It has been found that films with good crystallographic quality require quite long purging times, even above $10 \mathrm{~s} \mathrm{[7].}$ Therefore we expected that shortening of purging times would shift a structure of the films from polycrystalline towards amorphous one. The ALD growth processes were performed at $100^{\circ} \mathrm{C}, 130{ }^{\circ} \mathrm{C}$, and $200^{\circ} \mathrm{C}$.

\section{Results and discussion}

Atomic force microscopy (AFM) images show that the obtained films are atomically flat and the surface roughness, defined by the root mean square (RMS) value, is about $3 \mathrm{~nm}$ (see Fig. 1, down), so it is only slightly higher than in case of $\mathrm{ZnO}$ films grown with purging time of $8 \mathrm{~s}$ and $20 \mathrm{~s}[6,7]$. This level of the surface roughness is appropriate for electronic applications. Scanning electron microscopy (SEM) images (Fig. 1, top) show a granular microstructure with grain diameters from $25 \mathrm{~nm}$ to $75 \mathrm{~nm}$ depending on ALD process parameters. The grain size was approximately $50-75 \mathrm{~nm}$ for $130^{\circ} \mathrm{C}$ growth temperature, while at the temperature of $200^{\circ} \mathrm{C}$ it was slightly smaller, below $50 \mathrm{~nm}$.
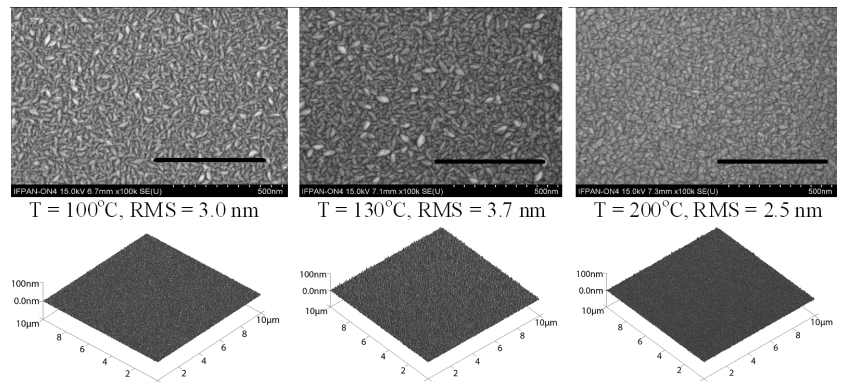

Fig. 1. SEM (top) and AFM (bottom) images of $100 \mathrm{~nm}$ thick $\mathrm{ZnO}$ films grown with purging time $2 \mathrm{~s}$. The $500 \mathrm{~nm}$ scale is shown at SEM images. AFM images cover an area of $10 \times 10 \mu \mathrm{m}^{2}$.

Room temperature photoluminescence (RT PL) spectra reveal that all the samples show a band-edge PL at $377 \mathrm{~nm}$. For samples obtained at $100^{\circ} \mathrm{C}$ and $130^{\circ} \mathrm{C}$ a wide defect-related PL band between $500 \mathrm{~nm}$ and $700 \mathrm{~nm}$ was also seen, while it is absent in PL spectra of $\mathrm{ZnO}$ films deposited at $200{ }^{\circ} \mathrm{C}$. The defect-related band is significantly stronger when purging time is very short (see Fig. 2) and it is more than twice weaker when purging time exceeds $1 \mathrm{~s}$. Intensity of a band-edge PL increases slightly when purging time becomes longer. Both these effects demonstrate the influence of the purging time on the structural quality of the films. The peak observed at $540 \mathrm{~nm}$ is only a second harmonic of the $\alpha=270 \mathrm{~nm}$ excitation wavelength.

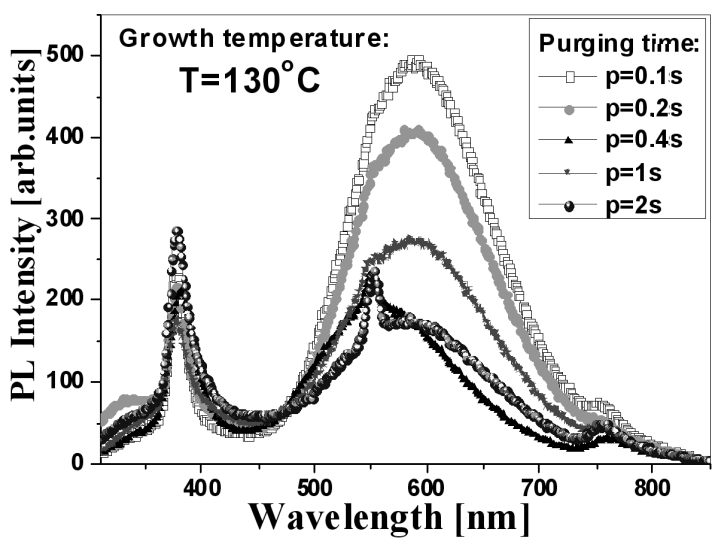

Fig. 2. Room temperature photoluminescence spectra of $\mathrm{ZnO}$ films about $100 \mathrm{~nm}$ thick deposited at $130{ }^{\circ} \mathrm{C}$ with different purging times (from $0.1 \mathrm{~s}$ to $2 \mathrm{~s}$ ).

Interesting results are provided by the Hall measurements that were obtained in the van der Pauw geometry using the RH2035 PhysTech GmbH system equipped with a permanent magnet producing a magnetic field $B=0.426 \mathrm{~T}$. As ohmic contacts to $\mathrm{ZnO}$, the e-beam evaporated bi-layers of $\operatorname{Ti}(100 \AA) / \mathrm{Au}(400 \AA)$ were used.

The Hall effect studies showed that the $\mathrm{ZnO}$ layers obtained at $200{ }^{\circ} \mathrm{C}$ are characterized by the $n$-type conductivity, with carrier mobility $20-22 \mathrm{~cm}^{2} /(\mathrm{Vs})$ and a high electron concentration $\left(\approx 4 \times 10^{19} \mathrm{~cm}^{-3}\right)$ that only weakly depends on the purging time.

On the other hand, the $\mathrm{ZnO}$ layers obtained at $100^{\circ} \mathrm{C}$ and $130^{\circ} \mathrm{C}$ with very short purging times $(0.1 \mathrm{~s}, 0.2 \mathrm{~s}$, $0.4 \mathrm{~s}$ ) behave differently. The Hall measurements reveal the $p$-type conductivity with a carrier concentration of about $1.5 \times 10^{16} \mathrm{~cm}^{-3}$. For $\mathrm{ZnO}$ films deposited at $130^{\circ} \mathrm{C}$ with longer purging times we observed the $n$-type conductivity while films deposited at $100{ }^{\circ} \mathrm{C}$ still show $p$-type conductivity, even for purging time $2 \mathrm{~s}$. We assume that these results can be slightly influenced by the electrical characteristic of the substrate. The $\mathrm{ZnO}$ films were deposited on a resistive $p$-type $\mathrm{Si}(001)$ substrate with carrier concentration of $1.2 \times 10^{12} \mathrm{~cm}^{-3}$ and mobility $316 \mathrm{~cm}^{2} /(\mathrm{V} \mathrm{s})$. Only samples deposited at temperatures $100{ }^{\circ} \mathrm{C}$ and $130^{\circ} \mathrm{C}$ with very short purging time reveal an effect of the $p$-type conductivity.

Some light on the observed effect is shed by the X-ray diffraction (XRD) studies. They show that all investigated $\mathrm{ZnO}$ samples were polycrystalline, even these deposited with very short pulsing times $(0.2 \mathrm{~s})$. In XRD spectra one can observe (10.0), (00.2), (10.1) and (11.0) crystallographic orientations. Their relative intensity depends on deposition temperature. Higher deposition temperature privilege the (00.2) crystallographic orientation. When we compare XRD spectra of $\mathrm{ZnO}$ films deposited with purging time $0.4 \mathrm{~s}$ at $100{ }^{\circ} \mathrm{C}, 130^{\circ} \mathrm{C}$ (both reveal the $p$-type conductivity) and $200^{\circ} \mathrm{C}$ (with the $n$-type conductivity) we see that the intensities of (10.0), (10.1) and (11.0) diffraction peaks are similar. The only dif- 
ference can be seen in both intensity and location of the (00.2) diffraction peak, which is much stronger for $\mathrm{ZnO}$ film deposited at $200^{\circ} \mathrm{C}$. Also its maximum is located at $2 \Theta$ angle $34.4^{\circ}$, while for films deposited at $100^{\circ} \mathrm{C}$ and $130^{\circ} \mathrm{C}$ it is observed slightly lower, at $2 \Theta$ angle $34.2^{\circ}$. This indicates that a change observed in the type of conductivity is related to the mechanical stress in the $\mathrm{ZnO} / \mathrm{Si}$ interface layer.

\section{Summary}

To summarize, we investigated a few series of very thin (70 nm to $110 \mathrm{~nm}) \mathrm{ZnO}$ films that were obtained in the ALD processes with very short purging times (from $0.1 \mathrm{~s}$ to $2 \mathrm{~s}$ ). The films were grown at temperatures $100^{\circ} \mathrm{C}$, $130^{\circ} \mathrm{C}$, and $200^{\circ} \mathrm{C}$ that are appropriate for deposition on organic substrates. The films show granular surface structure with the surface roughness about $3 \mathrm{~nm}$. RT PL spectra show a band-edge PL line at $377 \mathrm{~nm}$ and defect-related band. The intensity of the latter one anti-correlates with a purging time. The films grown at $100^{\circ} \mathrm{C}$ and $130^{\circ} \mathrm{C}$ with purging time below $1 \mathrm{~s}$ show $p$-type conductivity when deposited on a resistive silicon substrate. Based on the XRD studies we tentatively ascribe this effect to the stress in the $\mathrm{ZnO}$ sublayer near the $\mathrm{ZnO}$ /interface.

\section{Acknowledgments}

The research was partially supported by the European Union within European Regional Development Fund, through grant Innovative Economy (POIG.01.01.02-00$-008 / 08)$. The author D. Snigurenko was partially supported by the European Social Found through Human Capital Programme and Foundation for Academic Enterprise (in Polish original: "Fundacja Przedsiębiorczości Akademickiej").

\section{References}

[1] B. Park, K. Cho, S. Kim, S. Kim, Nanoscale Res. Lett. 6, 41 (2011).

[2] C. Weichsel, O. Pagni, A.W.R. Leitch, Semicond. Sci. Technol. 20, 840 (2005).

[3] S.J. Lim, S.J. Kwon, H. Kim, Appl. Phys. Lett. 91, 183517 (2007).

[4] J.J. Kyeong, Semicond. Sci. Technol. 26, 034008 (2011).

[5] E. Kasia, N. Huby, G. Tallarida, B. Kutrzeba-Kotowska, M. Perygo, S. Ferrari, F.C. Krebs, E. Guziewicz, M. Godlewski, V. Osinniy, G. Luka, Appl. Phys. Lett. 94, 143501 (2009).

[6] E. Guziewicz, M. Godlewski, T. Krajewski, Ł. Wachnicki, A. Szczepanik, K. Kopalko, A. WójcikGłodowska, E. Przeździecka, W. Paszkowicz, E. Łusakowska, P. Kruszewski, N. Huby, G. Tallarida, S. Ferrari, J. Appl. Phys. 105, 122413 (2009).

[7] I.A. Kowalik, E. Guziewicz, K. Kopalko, S. Yatsunenko, A. Wójcik-Głodowska, M. Godlewski, P. Dłużewski, E. Łusakowska, W. Paszkowicz, J. Cryst. Growth 311, 1096 (2009). 